\title{
Dificuldades presentes na adesão do pré-natal do parceiro mundialmente: Uma
}

\section{revisão integrativa}

\author{
Difficulties present in adhering to partner prenatal care worldwide: An integrative review \\ Dificultades presentes para adherirse a la atención prenatal de la pareja en todo el mundo: Una
} revisión integradora

\author{
Walesca Carvalho Amaral Batista \\ ORCID: https://orcid.org/0000-0003-3494-7481 \\ Prefeitura Municipal de Araruama, Brasil \\ E-mail: walesca_dasilva@hotmail.com \\ Rosana de Carvalho Castro \\ ORCID: https://orcid.org/0000-0003-0379-9244 \\ Universidade Federal Fluminense, Brasil \\ E-mail: rcastro@id.uff.br \\ Isabel Cristina Ribeiro Regazzi \\ ORCID: https://orcid.org/0000-0002-0662-9446 \\ Universidade Federal Fluminense, Brasil \\ E-mail: violetafloral@hotmail.com \\ Carina Oliveira Motta \\ ORCID: https://orcid.org/0000-0001-9336-7239 \\ Prefeitura Municipal de Rio das Ostras, Brasil \\ E-mail: carinamotta@id.uff.br \\ Elida Borges Lopes \\ ORCID: https://orcid.org/0000-0002-4163-3766 \\ Universidade Federal Fluminense, Brasil \\ E-mail: elidaborges@id.uff.br \\ Giúlia Kamille de Medeiros Padilha \\ ORCID: https://orcid.org/0000-0002-9537-5731 \\ Escola Politécnica de Saúde Joaquim Venâncio, Brasil \\ E-mail: giuliapadilha@id.uff.br \\ Yasmim Campos dos Santos Maia \\ ORCID: https://orcid.org/0000-0001-7816-701X \\ Universidade Federal Fluminense, Brasil \\ E-mail: yasmiimcampoos@gmail.com
}

\begin{abstract}
Resumo
Objetivo: Identificar através das produções científicas os fatores que intervêm na adesão ao pré-natal do parceiro nos últimos dez anos. Método: foi realizada uma revisão integrativa nas as seguintes bases de dados: Scientific Eletronic Library Online (SciELO); Literatura Latino-Americana e do Caribe em Ciências da Saúde (LILACS); Medical Literature Analysis and Retrieval Sistem Online (MEDLINE); e Cumulative Index to Nursing and Allied Health Literature (CINAHL). Resultado: Dentre os 07 artigos encontrados, 05 foram realizados no Brasil, nos anos de 2010 , 2012, 2017 e 2018; e 02 foram publicados na Inglaterra nos anos de 2013 e 2015. Os fatores que intervêm na adesão ao pré-natal do parceiro nos últimos dez anos, foram agrupados em duas (2) categorias: a) Vivência do homem/pai durante o pré-natal e b) Não presença do homem/pai durante o pré-natal. Conclusão: Mesmo com a identificação da vontade do homem em querer participar desse processo e se preparar para o nascimento do filho, entretanto, no Brasil ainda se encontra barreiras culturais e institucionais que o impedem de efetivar seu direito. Já em outros países desenvolvidos, a maioria dos parceiros mostrou-se muito positiva em relação à gravidez, presentes no pré-natal e ciente sobre seus direitos a licença de paternidade.
\end{abstract}

Palavras-chave: Paternidade; Cuidado pré-natal; Atenção primária à saúde.

\begin{abstract}
Objective: To identify through scientific productions the factors that intervene in adherence to the partner's prenatal care in the last ten years. Method: an integrative review was carried out in the following databases: Scientific Eletronic Library Online (SciELO); Latin American and Caribbean Literature on Health Sciences (LILACS); Medical Literature Analysis and Retrieval Sistem Online (MEDLINE); and Cumulative Index to Nursing and Allied Health Literature (CINAHL). Result: Among the 07 articles found, 05 were made in Brazil, in the years 2010, 2012, 2017 and 2018; and 02 were published in England in the years 2013 and 2015. The factors that intervene in the partner's
\end{abstract}


prenatal adherence in the last ten years were grouped into two (2) categories: a) Man / father's experience during the pre- natal and b) No presence of the man / father during the prenatal period. Conclusion: Even with the identification of the man's will to want to participate in this process and prepare for the birth of the child, however, in Brazil there are still cultural and institutional barriers that prevent him from realizing his right. In other developed countries, on the other hand, most partners were very positive about pregnancy, present in prenatal care and aware of their rights to paternity leave.

Keywords: Paternity; Prenatal care; Primary health care.

\section{Resumen}

Objetivo: Identificar, a través de producciones científicas, los factores involucrados en la adherencia de la pareja a la atención prenatal en los últimos diez años. Método: se realizó una revisión integradora en las siguientes bases de datos: Scientific Electronic Library Online (SciELO); Literatura Latinoamericana y del Caribe en Ciencias de la Salud (LILACS); Sistema de análisis y recuperación de literatura médica en línea (MEDLINE); e Índice acumulativo de literatura sobre enfermería y salud afín (CINAHL). Resultado: De los 07 artículos encontrados, 05 fueron realizados en Brasil, en 2010, 2012, 2017 y 2018; y 02 se publicaron en Inglaterra en 2013 y 2015. Los factores que intervienen en la adherencia de la pareja a la atención prenatal en los últimos diez años se agruparon en dos (2) categorías: a) Experiencia del hombre / padre durante el período prenatal. Navidad. y b) No presencia del hombre / padre durante el cuidado prenatal. Conclusión: Aún con la identificación de la voluntad de los hombres de participar en este proceso y prepararse para el nacimiento de su hijo, sin embargo, en Brasil aún existen barreras culturales e institucionales que les impiden cumplir con su derecho. En otros países desarrollados, sin embargo, la mayoría de las parejas eran muy positivas sobre el embarazo, estaban presentes en la atención prenatal y eran conscientes de sus derechos a la licencia por paternidad.

Palabras clave: Paternidad; Atención prenatal; Atención primaria de salud.

\section{Introdução}

É na gestação que acontece a transição para parentalidade, ocorrendo assim para os novos pais variadas mudanças e adaptações, tanto em nível psicológico quanto biológico servindo como preparação para os novos papéis que terão de assumir. Porém, em diversos países, incluindo o Brasil, observa-se que culturalmente a sociedade sempre atribuiu a mulher grandes responsabilidades decorrentes da sua condição biológica de gestar, parir e amamentar, considerando sua natureza maternal, e o parceiro ficando com a responsabilidade de apenas provedor e mantedor do lar, como se este fosse incapaz de cuidar dos próprios filhos (Salmela-Aro, Nurmi, Saisto \& Halmesmäki, 2000).

O modo em que masculinidade é vista pela sociedade traz fatores negativos para a vida e saúde dos próprios homens. É necessário novo estímulo e a valorização de aspectos da masculinidade capazes de alterar esta condição, promovendo o autocuidado e o cuidado com outro, como a paternidade. Para isto, é necessário que a interação do homem com seu filho (a) inicie-se antes da concepção, porém, poucas são as pesquisas voltadas para identificar e demostrar a importância das vivências de paternidade no período anterior ao nascimento e mesmo durante o parto (Martins, Barros \& Mororó, 2018).

A gestação traz um significado repleto de emoções para a família, mas para o sistema de saúde requer uma demanda extensa de ações. Nos últimos anos o tema sobre a importância do envolvimento consciente e ativo do parceiro/pai tem emergindo cada vez mais, com novos debates, ações e mudança de olhar por parte dos pesquisadores e profissionais da saúde (Brasil, 2016). Mas, o Brasil ainda precisa evoluir bastante sobre a percepção de exclusão dos pais nos serviços públicos, um problema ainda atual e que pode ser explicado pela pouca infraestrutura física, ausência de capacitações e descrédito dos profissionais sobre esse público em relação aos homens, principalmente os de classes mais baixas (Henz, Medeiros \& Salvadori, 2017).

Por causa desses fatores, a Política Nacional de Atenção Integral à Saúde do Homem (PNAISH) instituída pela Portaria GM/MS n 1.944, de 27 de agosto de 2009, tem como objetivo facilitar e ampliar o acesso da população masculina, na faixa etária entre 20 e 59 anos, às ações e aos serviços de assistência integral à saúde da Rede SUS com qualidade. A PNAISH faz a inclusão dos temas da saúde sexual e reprodutiva paternidade e cuidado, por meio do Pré-Natal do Parceiro, nas ações 
voltadas para o planejamento reprodutivo como um meio para qualificação da atenção à gestação, ao parto e ao nascimento e os vínculos afetivos familiares dos usuários e das usuárias nos serviços ofertados (Brasil, 2016).

A Paternidade e Cuidado é um dos eixos prioritários da PNAISH relacionando o engajamento dos homens nas ações do planejamento reprodutivo, no acompanhamento do pré-natal, no parto e pós-parto de suas parceiras e nos cuidados no desenvolvimento da criança, trazendo uma melhora de qualidade de vida e a construção de vínculos afetivos saudáveis. Nesse contexto, o Pré-Natal do Parceiro busca ser uma das principais 'portas de entrada' aos serviços ofertados pela Atenção Básica em saúde à população, ao enfatizar ações como à prevenção, à promoção, autocuidado e até mesmo adoção de estilos de vida mais saudáveis (Brasil, 2018).

A Estratégia Pré-Natal do Parceiro, possibilita que o homem acompanhe a parceira nas consultas de pré-natal realizadas nas Unidades Básicas de Saúde, também possa realizar algumas ações de prevenção à saúde, como procedimento de aferição de medidas antropométricas (peso, altura, IMC); aferição de pressão arterial; exames preventivos de rotina, como glicemia em jejum, hemograma, entre outros; testes rápidos para diagnosticar sífilis, HIV/aids e hepatites B e C; atualizar seu cartão de vacinação; realizar consultas com o dentista para saber como anda sua saúde bucal; participar de atividades educativas desenvolvidas durante as consultas de pré-natal; e, além disso, ficar atualizado sobre seus direitos paterno (Brasil, 2018).

Em relação aos direitos do parceiro no pré-natal, o Brasil foi um dos primeiros países a oferecer a licença-paternidade no mundo, em 1943. De acordo com a Constituição Federal $/ 88 \mathrm{em}$ seu artigo $7^{\circ}$, XIX e art.10, $\S^{\circ}$, do Ato das Disposições Constitucionais Transitórias -ADCT os pais têm direito a 5 dias de licença paternidade. Porém, com o objetivo de ampliar esse direito, no dia 08 de Março de 2016 foi sancionada a Lei 13.257/2016, que dispõe sobre as políticas públicas para primeira infância. Na lei, existem artigos específicos ligados ao exercício da paternidade ativa e consciente, ampliando a licença paternidade para os funcionários das empresas cidadãs possuindo assim, o direito a 20 dias. Destacando também no inciso II, parágrafo $1^{\circ}$, artigo 38 , que o empregado requeira no prazo de 2 (dois) dias úteis após o parto e comprove participação em programa ou atividade de orientação sobre paternidade responsável para ter direito ao benefício da licença (Brasil, 2016).

No mundo todo, entre os anos de 1994 e 2013, o número de países que concedem o direito à licença-paternidade aumentou de 41 para 79, na maior parte deles $90 \%$ o benefício é remunerado. Com a duração da licença varia de 1 a 90 dias, com benefícios relativamente mais extensos nos países europeus como Finlândia, Islândia, Lituânia, Portugal e Eslovênia, equivalente a duas semanas a mais (Brasil, 2016).

A evasão paterna no pré-natal nas Unidades Básicas de Saúde, ocorrem suspostamente pela falta de informações e também pelo déficit de conhecimentos do casal sobre esse assunto. Ocorrendo a necessidade então de propor ações para o desempenho do pré-natal com a presença do pai juntamente com a gestante (Bonim, Andrade, Nunes \& Looze, 2020).

Quando o homem acompanha sua parceira nas consultas de pré-natal, já desenvolve um preparo emocional para exercer a paternidade, tornando o momento da gestação mais humanizado. Ocorre uma necessidade de o homem proporcionar à sua companheira apoio emocional, para que consequentemente ela se sinta mais segura, fazendo com que o casal possa compartilhar as alegrias do nascimento, o que gera maior proximidade e intensificação do relacionamento. Com esta participação o homem torna a sua companheira o foco de atendimento, além de fortalecer seus potencias e conhecimento para auxiliar a gestante, colocando-o em uma posição ativa e não somente de expectador no que diz respeito ao nascimento (Silva $e t$ al., 2013).

O companheiro da mulher pode ser considerado um acompanhante ideal durante o pré-natal e o parto, devido a fatores como a formação de vínculo e a representação de laços de família, pois, ao acompanhar o nascimento do filho, ele estaria afirmando sua paternidade e valorizando seu papel (Holanda et al., 2018). 
O pai se torna uma figura importante no período de pré-natal não apenas pelo acompanhamento da gestante, mas para a construção da identidade de pai, contribuindo para o seu envolvimento afetivo com o bebê. Durante os noves meses os pais devem ser estimulados a participar das consultas de pré-natal e participação de atividade como escolhas como compra de roupas, móveis, organização e planejamento das atividades diárias (Menezes, Floriano \& Lopes, 2021).

A Política Nacional de Atenção Integral à Saúde do Homem, cita que "é necessário conscientizar os homens do dever e do direito à participação no planejamento reprodutivo". Assim, a paternidade não deve ser vista apenas como uma obrigação legal, mas também como um direito do homem a participar de todo o processo, desde o início do planejamento familiar, a participação e o acompanhamento da gravidez, do parto, do pós-parto e posteriormente na educação da criança (Coelho, Schwarz, Bolsoni \& Conceição, 2018). O objetivo foi identificar através das produções científicas os fatores que intervêm na adesão ao pré-natal do parceiro nos últimos dez anos.

\section{Metodologia}

Revisão Integrativa da Literatura, de abordagem qualitativa, que cumpriu seis etapas: 1) identificação do tema e seleção da questão de pesquisa; 2) estabelecimento de critérios de inclusão e exclusão de estudos; 3) definição das informações a serem extraídas dos estudos selecionados dos estudos; 4) avaliação dos estudos incluídos; 5) interpretação dos resultados e 6) apresentação da revisão/síntese do conhecimento (Ercole, Melo \& Alcoforado, 2014).

Cujo tema foi pré-natal do parceiro e sua respectiva questão de pesquisa: Quais são os fatores que intervêm na adesão do pré-natal do parceiro apontados nas evidências científicas nos últimos 10 anos?

As buscas foram realizadas nas seguintes bases de dados: Scientific Eletronic Library Online (SciELO); Literatura Latino-Americana e do Caribe em Ciências da Saúde (LILACS); Medical Literature Analysis and Retrieval Sistem Online (MEDLINE); e Cumulative Index to Nursing and Allied Health Literature (CINAHL). Os descritores utilizados foram Paternidade, Pré-Natal e Gravidez. Para a busca, eles foram associados em dupla e de todas as possíveis combinações com o operador booleano "AND".

Para a seleção dos artigos foram considerados os seguintes critérios de inclusão: artigos científicos publicados entre 2009 a 2020 online, publicações disponíveis na íntegra, publicações nos idiomas português, inglês e espanhol, publicações sobre a realidade nacional e internacional. Entre os critérios de exclusão estão os estudos duplicados, artigos de reflexão, revisões de literatura narrativa e integrativa e cartas.

A escolha do recorte temporal para busca das evidências científicas deu-se a partir de 2009, em virtude do surgimento da Política Nacional de Atenção Integral à Saúde do Homem (PNAISH), instituída pela Portaria GM/MS nº 1.944, tendo como um dos eixos prioritários: a Paternidade e Cuidado.

\section{Resultados}

Observa-se que após os distintos cruzamentos nas diferentes bases de dados como: Paternidade and Pré-Natal e Paternidade and Gravidez gerou um total de 447 artigos que após leitura de títulos, somente 32 foram selecionados para leitura dos resumos, 10 para leitura na íntegra e 7 selecionados para composição desta revisão $\mathrm{O}$ fluxo do processo de seleção e exclusão dos estudos desta revisão integrativa se encontra representado na figura 1. 
Figura 1 - Fluxo do processo de seleção e exclusão dos estudos. Rio das Ostras, RJ, Brasil.

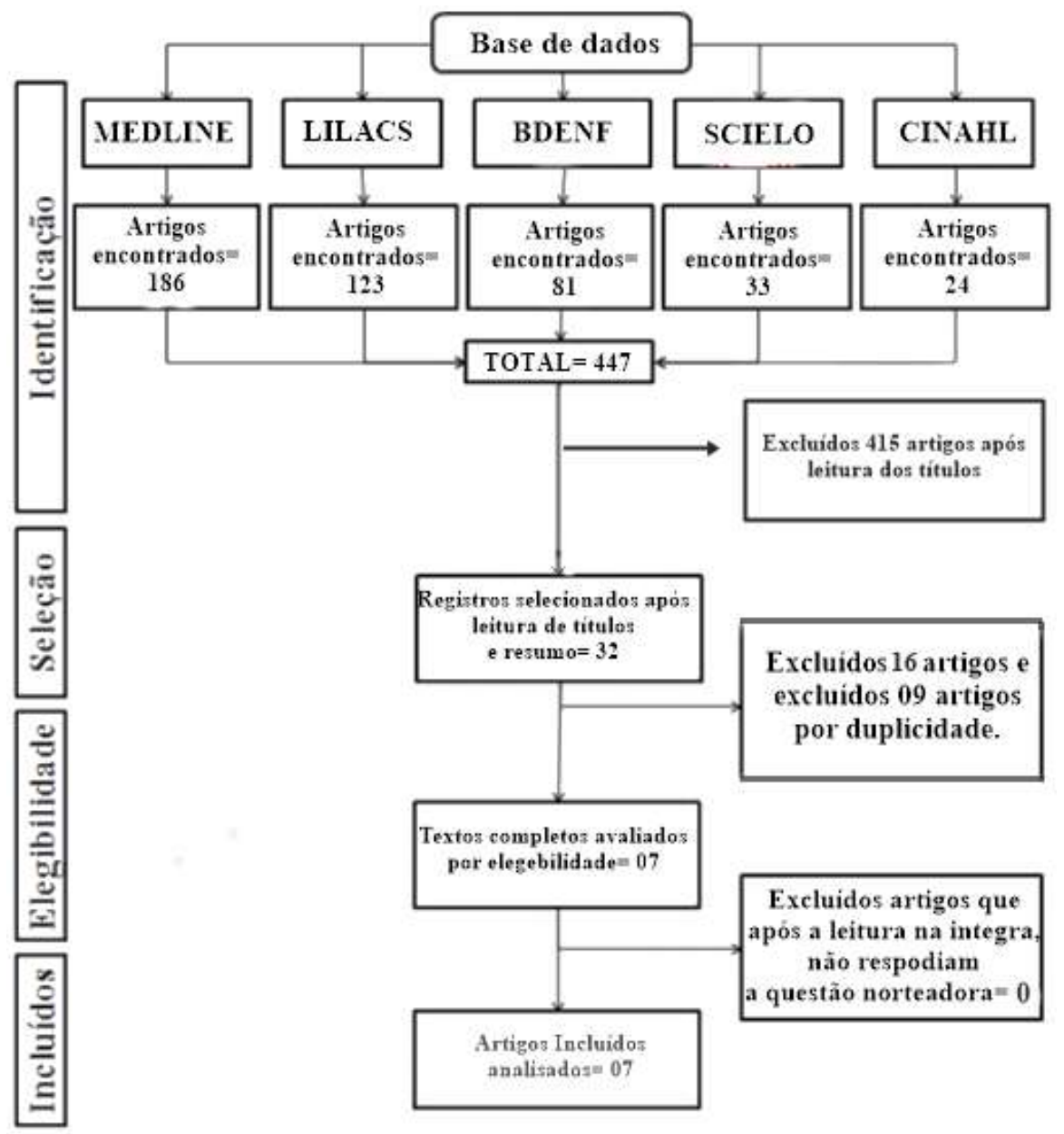

Fonte: Elaborado pelos autores.

Percebe-se na figura 1 que a busca foi realizada em cinco bases de dados, com o maior número de manuscritos na MEDLINE e menor na CINAHL. Com o percurso do fluxo de seleção e exclusão dos estudos foi possível identificar e eleger aqueles com adequação ao objetivo e aos critérios de inclusão desta revisão e a composição final somente de 7 artigos que atenderam a elegibilidade. Os artigos foram analisados e sintetizados, agrupando as principais informações, sendo estes: título, revista, ano de publicação, local do estudo, objetivo e resultado encontrado. Os artigos selecionados se encontram descritos no quadro 1. 
Quadro 1 - Caracterização dos artigos selecionados sobre os fatores intervenientes da adesão do pré-natal do parceiro.

\begin{tabular}{|c|c|c|c|c|c|}
\hline $\begin{array}{l}\mathrm{N}^{0} \text { do } \\
\text { artigo }\end{array}$ & Título & $\begin{array}{c}\text { Revista, ano } \\
\text { de publicação }\end{array}$ & $\begin{array}{c}\text { Local do } \\
\text { estudo }\end{array}$ & Objetivo & Resultados \\
\hline $\begin{array}{c}\text { Artigo } \\
01\end{array}$ & $\begin{array}{l}\text { Percepções e } \\
\text { experiências de } \\
\text { homens relativas } \\
\text { ao pré-natal e } \\
\text { parto de suas } \\
\text { parceiras. }\end{array}$ & $\begin{array}{l}\text { Rev. enferm. } \\
\text { UERJ, Rio de } \\
\text { Janeiro, } 2010 . \\
\text { LILACS }\end{array}$ & $\begin{array}{l}\text { Bahia- } \\
\text { Brasil. }\end{array}$ & $\begin{array}{l}\text { Analisar a participação de } \\
\text { homens no pré-natal e parto de } \\
\text { suas parceiras }\end{array}$ & $\begin{array}{l}\text { Entre os motivos apresentados para não } \\
\text { participarem das consultas de pré-natal, os } \\
\text { entrevistados alegaram falta de tempo, } \\
\text { principalmente devido ao trabalho, além do } \\
\text { desinteresse de participar deste atendimento: } \\
\text { Eu já fui levar [...], mesmo assim nem fiquei, } \\
\text { cheguei lá e saí. Até me interessa, mas toma muito } \\
\text { o meu tempo... ai eu tenho que sair um pouco e } \\
\text { tenho que trabalhar! (E8) } \\
\text { Não, nunca me importei não... naquele tempo [na } \\
\text { gravidez do primeiro filho] a gente [ele e a } \\
\text { parceira] nunca ligava. Até hoje, ainda não vou... } \\
\text { [acompanhar a parceira no pré-natal]. (E5) } \\
\text { É notório que, para muitos homens, a paternidade } \\
\text { não é sentida durante o processo da gestação, } \\
\text { havendo, ainda, alguns casos que mesmo após o } \\
\text { nascimento do filho, esse sentimento permaneça } \\
\text { fragilizado e reflita no distanciamento desse } \\
\text { processo, conforme demonstrado neste estudo. }\end{array}$ \\
\hline $\begin{array}{c}\text { Artigo } \\
02\end{array}$ & $\begin{array}{l}\text { A ausência do } \\
\text { companheiro nas } \\
\text { consultas de pré- } \\
\text { natal: desafios e } \\
\text { conquistas }\end{array}$ & $\begin{array}{l}\text { R. pesq.: cuid. } \\
\text { fundam. online } \\
2012 . \\
\text { BDENF }\end{array}$ & $\begin{array}{l}\text { Brasil- } \\
\text { Rio de } \\
\text { Janeiro }\end{array}$ & $\begin{array}{l}\text { Analisar a inserção e visão do } \\
\text { companheiro acerca da } \\
\text { assistência pré-natal, } \\
\text { identificar e analisar os } \\
\text { motivos que levam a uma } \\
\text { parcela desses companheiros a } \\
\text { não acompanharem suas } \\
\text { mulheres gestantes nas } \\
\text { consultas de pré-natal }\end{array}$ & $\begin{array}{l}\text { As unidades de saúde por sua vez devem } \\
\text { estabelecer rotinas e criar condições físicas para } \\
\text { que esse profissional possa desenvolver bem o seu } \\
\text { papel. Muitas vezes o próprio profissional não } \\
\text { conhece a diferença que faz a presença do pai no } \\
\text { contexto do prénatal, às vezes acredita que o } \\
\text { homem irá atrapalhar, quando na verdade ele tem } \\
\text { tudo para ajudar. }\end{array}$ \\
\hline $\begin{array}{c}\text { Artigo } \\
03\end{array}$ & $\begin{array}{l}\text { O envolvimento } \\
\text { dos pais na } \\
\text { gravidez e no } \\
\text { parto: evidências } \\
\text { de uma pesquisa } \\
\text { nacional }\end{array}$ & $\begin{array}{l}\text { BMC } \\
\text { Pregnancy and } \\
\text { Childbirth, } \\
2013 . \\
\text { CINAHL }\end{array}$ & Inglaterra & $\begin{array}{l}\text { Entender quem estava } \\
\text { envolvido durante a gravidez e } \\
\text { parto, de que maneira e como } \\
\text { o envolvimento paterno pode } \\
\text { influenciar a aceitação de } \\
\text { serviços por uma mulher, } \\
\text { perceções de cuidados e } \\
\text { resultados maternos. }\end{array}$ & $\begin{array}{l}\text { Mais de } 80 \% \text { dos pais ficaram "satisfeitos ou" } \\
\text { felizes "em com a gravidez, mais da metade dos } \\
\text { homens foram presentes no teste de gravidez, em } \\
\text { um ou mais exames pré-natais e quase todos } \\
\text { estavam presentes no ultrassom, em exames e no } \\
\text { parto. Três quartos dos pais tiraram licença por } \\
\text { paternidade e, durante o período pós-natal, a } \\
\text { maioria pais ajudaram com os cuidados do recém- } \\
\text { nascido. }\end{array}$ \\
\hline $\begin{array}{c}\text { Artigo } \\
04\end{array}$ & $\begin{array}{l}\text { O que os homens } \\
\text { querem da } \\
\text { triagem pré- } \\
\text { natal? } \\
\text { Constatações de } \\
\text { um estudo de } \\
\text { entrevista na } \\
\text { Inglaterra }\end{array}$ & $\begin{array}{c}\text { Midwifery } 31, \\
2015 . \\
\text { CINAHL }\end{array}$ & Inglaterra & $\begin{array}{l}\text { No Reino Unido, as parteiras } \\
\text { estão enfrentando uma política } \\
\text { de incluir homens no pré-natal, } \\
\text { e os homens logo receberão } \\
\text { licença de paternidade para } \\
\text { permitir seu envolvimento. } \\
\text { Como resultado, mais homens } \\
\text { poderão participar triagem, } \\
\text { apoio às mulheres e } \\
\text { participação na tomada de } \\
\text { decisões. Portanto, realizamos } \\
\text { uma exploração do que estar } \\
\text { envolvido significa para os } \\
\text { homens e o que eles querem da } \\
\text { triagem pré-natal e parteiras. }\end{array}$ & $\begin{array}{l}\text { Foram construídos três temas e mostramos que (1) } \\
\text { em gestações normais, os homens sabiam pouco } \\
\text { sobre o rastreio, e estavam felizes por as parteiras } \\
\text { assumirem o controlo durante as consultas, (2) em } \\
\text { casos de gestações complicados, os homens } \\
\text { queriam estar mais ativamente envolvidos, mas } \\
\text { alguns perceberam que enfrentavam suspeitas de } \\
\text { ser coercivo ao expressar opiniões, e (3) ao longo } \\
\text { do tempo, os homens tornaram-se mais adeptos de } \\
\text { comunicar com parteiras, mas algumas } \\
\text { desvincularam do pré-natal por causa da má á } \\
\text { comunicação com as parteiras e/ou uma falta de fé } \\
\text { nos benefícios do pré-natal. }\end{array}$ \\
\hline $\begin{array}{c}\text { Artigo } \\
05\end{array}$ & $\begin{array}{c}\text { A inclusão } \\
\text { paterna durante o } \\
\text { pré-natal }\end{array}$ & $\begin{array}{l}\text { Rev Enferm } \\
\text { Atenção } \\
\text { Saúde. } 2017 . \\
\text { BDENF }\end{array}$ & Brasil & $\begin{array}{c}\text { Investigar a participação } \\
\text { paterna durante o pré-natal em } \\
\text { um Centro de Atenção à Saúde } \\
\text { da Mulher }\end{array}$ & $\begin{array}{l}\text { A forma de participação paterna aparece nos } \\
\text { discursos como proporcionar amparo econômico e } \\
\text { apoio emocional e afetivo. A falta de flexibilidade } \\
\text { de horários das consultas, que coincide com os } \\
\text { seus horários de trabalho, dificulta a participação } \\
\text { nas consultas. }\end{array}$ \\
\hline $\begin{array}{c}\text { Artigo } \\
06\end{array}$ & $\begin{array}{l}\text { A visão das } \\
\text { gestantes acerca } \\
\text { da participação } \\
\text { do homem no } \\
\text { processo } \\
\text { gestacional }\end{array}$ & $\begin{array}{l}\text { Revista de } \\
\text { Enfermagem } \\
\text { do Centro- } \\
\text { Oeste Mineiro, } \\
2017 . \\
\text { LILACS }\end{array}$ & $\begin{array}{c}\text { Viçosa, } \\
\text { Minas } \\
\text { Gerais- } \\
\text { Brasil }\end{array}$ & $\begin{array}{c}\text { Analisar a visão das gestantes } \\
\text { quanto à participação do } \\
\text { homem durante o processo } \\
\text { gestacional e as consultas de } \\
\text { pré-natal }\end{array}$ & $\begin{array}{l}\text { A justificativa mais prevalente para a não } \\
\text { participação do companheiro nas consultas está } \\
\text { relacionada ao horário de trabalho deste. Sete } \\
\text { mulheres responderam que o horário de } \\
\text { atendimento às gestantes era inapropriado para } \\
\text { que companheiro pudesse acompanhá-la. Essa } \\
\text { situação evidencia a importância da melhor }\end{array}$ \\
\hline
\end{tabular}




\begin{tabular}{|c|c|c|c|c|c|}
\hline & & & & $\begin{array}{l}\text { adequação dos horários ofertados pelos serviços } \\
\text { de saúde na atenção à saúde da mulher grávida e, } \\
\text { ou a garantia legal da ausência paterna das } \\
\text { atividades laborais nos horários das consultas de } \\
\text { pré-natal, a fim de permitir sua participação. }\end{array}$ \\
\hline $\begin{array}{c}\text { Artigo } \\
07\end{array}$ & $\begin{array}{c}\text { A participação } \\
\text { do parceiro na } \\
\text { rotina pré-natal } \\
\text { sob a perspectiva } \\
\text { da mulher } \\
\text { gestante }\end{array}$ & $\begin{array}{c}\text { Rev Fund Care } \\
\text { Online, 2018. } \\
\text { LILACS }\end{array}$ & $\begin{array}{c}\text { Mato } \\
\text { Grosso- } \\
\text { Brasil. }\end{array}$ & $\begin{array}{c}\text { Analisar como a gestante } \\
\text { percebe a participação do } \\
\text { parceiro na rotina pré-natal. }\end{array}$ & $\begin{array}{l}\text { Das participantes do estudo, apenas uma teve } \\
\text { acompanhamento integral do parceiro, outras } \\
\text { cinco relataram a presença apenas na realização da } \\
\text { ultrassonografia } \\
\text { obstétrica. Daquelas que } \\
\text { relataram ausência, o trabalho foi apontado como } \\
\text { principal fator, também se observou que questões } \\
\text { de gênero influenciam nesta ausência, pois a } \\
\text { gestação é vista como momento exclusivo da } \\
\text { mulher }\end{array}$ \\
\hline
\end{tabular}

Fonte: Elaborado pelos autores.

Do total de 7 artigos, 05 foram realizados no Brasil, nos anos de 2010, 2012, 2017 e 2018; e 02 foram publicados na Inglaterra nos anos de 2013 e 2015. Desses 3 foram encontrados na base de dados LILACS, 2 na CINAHL e 2 na BDENF. Nesse quadro é importante observar a síntese dos resultados de cada artigo.

\section{Discussão}

\subsection{Categoria I: Não presença do homem/pai durante as consultas de pré-natal}

Os estudos mostram que os fatores que intervêm na adesão da participação do pai no cuidado ao pré-natal estão relacionados com os aspectos pessoais e financeiro do homem, desconhecimento e/ou falta envolvimento por parte do profissional que oferta o cuidado e estrutura física do local de acompanhamento do processo gestacional.

No âmbito nacional a questão trabalhista foi o entrave mais citado. A questão da sobrecarga de trabalho e o cansaço decorrente, os horários de trabalho coincidentes com as consultas de pré-natal impedem a inclusão e participação dos pais neste momento. Com isto os pais muitas vezes ficam presos ao seu papel de provedor, apesar do interesse em participar mais efetivamente do processo de nascer e das atividades que envolvem a gestação, perdendo esta oportunidade única em sua vida de acompanhar a evolução gestacional daquele filho (a) (Oliva, Nascimento \& Santo, 2010; Cabrita, Silveira, Souza \& Alves, 2012; Costa \& Taquette, 2017; Henz et al., 2017; Cardoso, Silva Junior, Bonatti, Santos \& Ribeiro, 2018).

A situação trabalhista é uma das barreiras mais significativas que estão impedindo a presença do pai nas consultas pré-natais. Mesmo que no contexto atual as a mulheres estejam inseridas no mercado de trabalho, o homem ainda é reconhecido como o provedor da família, demonstrando papéis de gênero marcadamente divididos. A própria legislação remete a essa compreensão quando se compara, por exemplo, a diferença de tempo entre a licença maternidade e paternidade (Costa \& Taquette, 2017).

Ao analisar os artigos, percebeu-se que o artigo 06 apresentou como justificativa da não presença do homem/pai durante as consultas de pré-natal está relacionada ao horário de trabalho deste. Ainda no artigo 07 o que surge como razões de não adesão do homem nas consultas de pré-natal relacionam-se às questões trabalhistas, isto é, o homem não é dispensado do seu emprego para acompanhar a companheira nas consultas de pré-natal. Já no artigo 01 a alegação reporta a falta de tempo devido ao trabalho.

A maioria dos pais não consegue ir ao serviço de saúde acompanhar a parceira, pois não lhe é permitido se ausentar do local de trabalho (Marques, 2015).

Enquanto no artigo 02 o que aparece como razão em não entrar nas consultas de pré-natal foi a questão de gênero, demonstrando que não é para homens participarem desse momento. 
A falta de material ilustrativo e educativo, como fotos de homens com bebês, folders sobre a participação paterna no processo gestatório, dentre outros meios educativos, pode induzir à interpretação de que se trata de um ambiente exclusivamente feminino, contribuindo para o distanciamento do homem desses espaços (Pesamosca, Fonseca \& Gomes, 2008).

\subsection{Categoria II: Vivência do homem/pai durante o pré-natal}

Os estudos realizados na Inglaterra demonstram que o envolvimento precoce como no pré-natal, entre os pais com seus filhos aumentaram nos últimos tempos. Tal envolvimento precoce melhora a cognição e socioemocional do desenvolvimento das crianças futuramente. Os pais ausentes têm sido associados a uma educação, comportamento e desenvolvimento correlacionado a baixa renda. E também a relação entre o profissional e os pais (Redshaw \& Henderson, 2013; Dheensa, Metcalfe \& Williams, 2015).

No artigo 04 que é um estudo internacional demonstra que, os homens sabiam pouco sobre o pré-natal, porém, estavam felizes pelas parteiras assumirem o controlo durante as consultas, ao longo do tempo, os homens tornaram-se mais adeptos de comunicar com parteiras, entretendo outros se desvincularam do pré-natal por causa da má comunicação com as parteiras e/ou pela falta de conhecimento dos benefícios do pré-natal.

Ainda em estudo internacional, o artigo 3 demonstra mais afetividade dos pais no pré-natal do parceiro em que mostrando que mais da metade dos homens foram presentes no teste de gravidez, quase todos estavam presentes no ultrassom, em exames de rotina e no parto. Utilizando a licença paternidade e, durante e depois do pré-natal, realizando cuidados do recém-nascido juntamente com a mãe.

No artigo 07 os discursos sobre a participação paterna estão relacionados ao amparo econômico e apoio emocional e afetivo, a falta de flexibilização de horários das consultas, que coincide com os horários de seus trabalhos, no que consequentemente dificulta a adesão da participação dos mesmos nesse cuidado.

Outro fator da não adesão está relacionado ao horário de funcionamento das Unidades de saúde que realizam o prénatal, citado como barreira para o acompanhamento das gestantes pelos parceiros, como demostrado em outro estudo (Henz et al., 2017; Cardoso et al., 2018).

A paternidade pode ser revigorada no processo de cuidar em consultas de pré-natal, tendo em vista os diversos fatores que essa atitude é capaz de proporcionar ao casal, e assim promover a igualdade de gênero (Sousa et al., 2021).

\section{Considerações Finais}

Em âmbito mundial as evidências científicas demonstram os fatores que intervêm na não participação paterna nas consultas de pré-natal. Os resultados deste estudo apontam para uma concentração limitada de artigos voltados para as dificuldades da participação do pai no período gestacional, o que reforça a necessidade de pesquisas nessa área para maior compreender esse processo de cuidado. Mesmo com a identificação da vontade do homem em querer participar desse processo e se preparar para o nascimento do filho, ele se depara com as barreiras culturais e institucionais do Brasil, o que o impedem de efetivar seu direito. Já em outros países desenvolvidos, a maioria dos parceiros mostrou-se muito positivo em relação à gravidez, presente no pré-natal e ciente sobre seus direitos, como a licença para paternidade, tendo como principal barreira do pré-natal do parceiro o vínculo fragilizado entre os profissionais da assistência aos pais.

Como um meio de incentivo e conscientização, o pré-natal se tornou um método para busca de adesão às novas ações propostas pelo Sistema de Saúde, no que se refere à saúde e ao cuidado do homem no Brasil. Além, de propor o reconhecimento acerca da importância da presença do pai no acompanhamento das consultas de pré-natal na qual devem ser divulgados e estimulados, facilitando e viabilizando a participação paterna nesse importante processo. 
Para que as barreiras culturais e institucionais deixem de ser fatores que intervêm a não adesão ao pré-natal do parceiro é necessário que sejam realizados estudos de coortes longitudinais no Brasil que acompanhem um grupo de casais desde a concepção até a primeira infância da prole que aderiram ao pré-natal e um grupo de homens que não aderiram ao prénatal. Estudo que traga em seus resultados os desfechos que esse processo pode proporcionar a toda família, já que em âmbito internacional alguns benefícios já foram descritos.

\section{Referências}

Brasil. Ministério da Saúde. (2016). Guia do pré-natal do parceiro para profissionais de saúde [Manual]. Rio de Janeiro: Ministério da Saúde.

Brasil. Ministério da Saúde. (2018). Como envolver o homem trabalhador no planejamento reprodutivo, pré-natal, parto e desenvolvimento da criança [Manual]. Brasília: Ministério da Saúde.

Bonim, S. S. S., Andrade, E. X., Nunes, V. \& Looze, J. T. T. (2020). A importância da participação do pai no acompanhamento do pré-natal. Rev. Saberes, Rolim de Moura, 13(1), 1-20. https://facsaopaulo.edu.br/wp-content/uploads/sites/16/2020/06/A-IMPORT\%C3\%82NCIA-DAPARTICIPA\%C3\%87\%C3\%83O-DO-PAI-NO-ACOMPANHAMENTO-DO-PR\%C3\%89-NATAL.pdf

Cabrita, B. A. C., Silveira, E. S., Souza, A. C. \& Alves, V. H. (2012). A ausência do companheiro nas consultas de pré-natal: desafios e conquistas. R. pesq.: cuid. fundam. online, 4(3), 2645-2654. Recuperado de https://pesquisa.bvsalud.org/portal/resource/pt/biblio-1029771

Caldeira, L. Á., Ayres, L. F. A., Oliveira, L. V. A. \& Henriques, B. D. (2017). A visão das gestantes acerca da participação do homem no processo gestacional Revista de Enfermagem do Centro-Oeste Mineiro, 7(e1417), 1-10. http://seer.ufsj.edu.br/index.php/recom/article/view/1417. doi: 10.19175/recom.v7i0.1417

Cardoso, V. E. P. S., Silva Junior, A. J., Bonatti, A. F., Santos, G. W. S. \& Ribeiro, T. A. N. (2018). The partner's involvement in the prenatal routine through the pregnant women perspective. J. res.: fundam. care. online, 10(3), 856-862. https://pesquisa.bvsalud.org/portal/resource/pt/biblio-906762. doi: 10.9789/2175-5361.2018.v10i3.856-862

Coelho, E. B. S., Schwarz, E., Bolsoni, C. C. \& Conceição, T. B. (2018). Política nacional de atenção integral a saúde do homem [Manual]. Florianópolis: Universidade Federal de Santa Catarina.

Costa, S. F. \& Taquette, S. R. (2017). Atenção à gestante adolescente na rede sus - o acolhimento do parceiro no pré-natal. Rev enferm UFPE on line, 11(supl. 5), 2067-2074. https://periodicos.ufpe.br/revistas/revistaenfermagem/article/view/23360. doi: 10.5205/1981-8963-v11i5a23360p2067-2074-2017

Dheensa, S., Metcalfe, A. \& Williams, R. (2015). What do men want from antenatal screening? Findings from an interview study in England. Midwifery, 31(1), 208-214. https://pubmed.ncbi.nlm.nih.gov/25242107/. doi: 10.1016/j.midw.2014.08.011

Ercole, F. F., Melo, L. S. \& Alcoforado, C. L. G. C. (2014). Revisão integrativa versus revisão sistemática. REME, 18(1), 9-11. https://www.reme.org.br/artigo/detalhes/904. doi: 10.5935/1415-2762.20140001

Henz, G. S., Medeiros, C. R. G. \& Salvadori, M. (2017). A inclusão paterna durante o pré-natal. Rev Enferm Atenção Saúde, 6(1), 52-66. http://seer.uftm.edu.br/revistaeletronica/index.php/enfer/article/view/2053

Holanda, S. M., Castro, R. C. M. B., Aquin, P. C., Pinheiro, A. K. B., Lopes, L. G. \& Martins, E. S. (2018). Influência da participação do companheiro no prénatal: satisfação de primíparas quanto ao apoio no parto. Texto contexto - enferm., 27(2), 1-10. https://www.scielo.br/j/tce/a/bw8qwZ8cJNR8WNqPx8QBF6c/abstract/?lang=pt. doi: 10.1590/0104-070720180003800016

Marques, S. S. (2015). Ampliar a licença-paternidade para despatriarcalizar o estado e a sociedade. Gênero \&amp; Direito, 4(1), 241-260. https://periodicos.ufpb.br/index.php/ged/article/view/24479. doi: 10.18351/2179-7137/ged.2015n1p241-260

Martins, A. C., Barros, G. M. \& Mororó, G. M. (2018). Paternidade na gestação e parturição: uma revisão integrativa. REFACS, 6(3), 485-493. http://seer.uftm.edu.br/revistaeletronica/index.php/refacs/article/view/2211. doi: 10.18554/refacs.v6i3.2211

Menezes, L. O., Floriano, T. V. N. \& Lopes, I. M. D. (2021). Impacto do perfil socioeconômico de gestantes e parceiros na avaliação da qualidade do prénatal. REAS/EJCH, 13(1), 1-8. https://acervomais.com.br/index.php/saude/article/view/5686. doi: 10.25248/reas.e5686.2021

Oliva, T. A., Nascimento, E. R. \& Santo, F. R. E. (2010). Percepções e experiências de homens relativas ao pré-natal e parto de suas parceiras. Rev. enferm. UERJ, 18(3), 435-440. Recuperado de https://pesquisa.bvsalud.org/portal/resource/pt/bde-19485

Pesamosca, L. G., Fonseca, A. D. \& Gomes, V. L. O. (2008). Percepção de gestantes acerca da importância do envolvimento paterno nas consultas pré-natal: um olhar de gênero. REME, 12(1), 182-188. https://www.reme.org.br/artigo/detalhes/255

Reberte, L. M. \& Hoga, L. A. K. (2010). A experiência de pais participantes de um grupo de educação para saúde no pré-natal. Cienc. enferm., 16(1), 105-114. https://scielo.conicyt.cl/scielo.php?pid=S0717-95532010000100012\&script=sci_abstract\&tlng=pt. doi: 10.4067/S0717-95532010000100012.

Redshaw, M. \& Henderson, J. (2013). Fathers' engagement in pregnancy and childbirth: evidence from a national survey. BMC Pregnancy and Childbirth, 13(70), 1-15. Retrieved from https://bmcpregnancychildbirth.biomedcentral.com/articles/10.1186/1471-2393-13-70

Salmela-Aro, K., Nurmi, J.-E., Saisto, T. \& Halmesmäki, E. (2000). Women's and men's personal goals during the transition to parenthood. Journal of Family Psychology, 14(2), 171-186. https://pubmed.ncbi.nlm.nih.gov/10870288/. doi: 10.1037/0893-3200.14.2.171 
Research, Society and Development, v. 10, n. 10, e70101018493, 2021

(CC BY 4.0) | ISSN 2525-3409 | DOI: http://dx.doi.org/10.33448/rsd-v10i10.18493

Silva, M. M. J., Cardoso, E. P., Calheiros, C. A. P., Rodrigues, E. O. M. A., Leite, E. P. R. C. \& Rocha, L. C. D. (2013). O envolvimento paterno na gestação sob o olhar de gênero. Rev enferm UFPE on line, 7(5), 1376-1381. https://periodicos.ufpe.br/revistas/revistaenfermagem/article/view/11622. doi: 10.5205/1981-8963-v7i5a11622p1376-1381-2013

Silva, P. S., Martello, J. M. S., Ruffoni, L. D. G., Andrade, J. C. \& Strada C. F. O. (2017). Participação dos pais no programa pré-natal masculino na cidade de santa terezinha de itaipu-pr. Revista Varia Scientia - Ciências da Saúde, 3(2), 173-180. http://e-revista.unioeste.br/index.php/variasaude/article/view/17677. doi: $10.48075 /$ vscs.v3i2.17677

Sousa, S. C., Oliveira, F. B. M., Sousa, F. C. A., Silva, S. S., Silva, W. C., Lima, K. L. A., Mendes, R. C., Hernandes, L. F., Miranda, L. S. C. \& Silva, R. A. (2021). Assistência ao pré-natal: participação do pai na gestação saudável. Research, Society and Development, 10(1), 1-11. https://rsdjournal.org/index.php/rsd/article/view/11330. doi: 10.33448/rsd-v10i1.11330 